\title{
IMPORTANCIA DE LOS HOSPEDEROS PRIMARIOS DE Myzus persicae Sulzer EN LA EPIDEMIOLOGÍA DEL PVY*
}

\author{
Jaime Ortego **
}

\begin{abstract}
RESUMEN
Se investigó el rol de los hospederos primarios de $M$. persicae, principal vector de PVY, en la epidemiología de este virus en Malargüe, Mendoza, Argentina, en un área protegida para la producción de tubérculos semilla de papa. En el ciclo 19891990, se realizó un relevamiento de este áfido sobre posibles hospederos primarios y secundarios. Se estudió el ciclo biológico de $M$. percicae en el área de estudio. Se efectuó un análisis morfométrico de individuos alados de esta especie, capturados en trampas amarillas de agua, lo que permitió determinar la proporción de formas holocíclicas y anholocíclicas presentes. Solamente Prunus percica y $P$. pissardii resultaron colonizados por $M$. persicae, constatándose además, que esta especie puede invernar también en forma partenogenética sobre hospederos secundarios. El análisis morfométrico indicó que las formas holocíclicas pueden representar entre el 50 y $100 \%$ de los individuos alados que visitan cultivos de papa al comienzo del ciclo, cuando las plantas son más sensibles al PVY. Esto indica que la relevancia de hospederos primarios especialmente durazneros ( $P$. persica), en a la dispersión temprana del virus.
\end{abstract}

Palabras claves adicionales: análisis morfométrico, holociclicos, anholociclicos, Prunus persica, dispersión de virus.

Aceptado para publicación: abril 2, 1994

* Trabajo realizado en Malargüe (Argentina) como parte de la Tesis del Magister en Ciencias Mención Protección Vegetal llevado a cabo en la Facultad de Ciencias Agrarias de la Universidad Austral de Chile. Valvivia, Chile. 1990.

** Ingeniero Agrónomo M. Sc.; Agencia de Extensión Rural, Instituto Nacional de Tecnología Agropecuaria (INTA). Casilla 114, 5613 Malargüe, Mendoza, Argentina. 


\section{IMPORTANCE OF PRIMARY HOSTS OF Myzus Persicae Sulzer IN THE EPIDEMIOLOGY OF PVY}

The role of the primary host of M persicae the main vector of PVY, in the epidemiology of this virus, was investigated in Malargüe, Mendoza, Argentina, a protected area for the production of seed potato tubers. In the cycle 1989-90 a survey of this aphid was made on the possible primary and secondary host and the biologic cycle of $M$. persicae was established in the studied area. A morphometric analysis of winged individuals caught in yellow water traps was made. This method permitted to determinate the proportion of holocyclic and anholocyclic forms. Only Prunus persicae and P. pissardii were colonized by $M$. persicae recording besides that this species may spend the winter in parthenogenetic form on secondary host. This morphometric analysis showed that holocyclic forms may representate between 50 and $100 \%$ of all winged individuals which visit potato crops at the beginning of the cycle, when the plants are more sensible to the PVY. This indicates that the presence of primary host, especially peach trees (P. persicae) is relevant to the early spread of this virus.

Additional index words: morphometric analysis, holocyclic, anholocyclic, Prunus persica, virus spreed

El PVY se ha convertido en uno de los principales problemas fitosanitarios en los programas de producción de tubérculos semilla de papa de la Argentina. En la actualidad no existen métodos de control químico satisfactorios que permitan disminuir la incidencia del PVY en áreas dedicadas a la producción de tubérculos de papa destinados a la siembra (12). Esto se debe a que, por tratarse de un virus que se transmite por áfidos de manera no persistente, los insecticidas no actúan lo suficientemente rápido como para evitar que las formas aladas que visitan los cultivos puedan dispersar el PVY (17).

Por otra parte, existe un gran número de especies de áfidos vectores que, aún sin ser colonizadores de papa, pueden transmitir el PVY durante las pruebas cortas que realizan para reconocer sus hospederos (11). 
El áfido Myzus persicae Sulzer es considerado por muchos autores (11, 18, 22) como el más eficiente vector del PVY. Actualmente esta distribuido en todo el mundo (2) y su polifagia (21) le permite producir grandes poblaciones de individuos alados que visitan y colonizan cultivos de papa. El momento en que se producen estos vuelos, es fundamental para la dispersión de las virosis transmitidas por Áfidos (16). El conocimiento de la biología y actividad de vuelo de los vectores, es de gran importancia para tomar medidas de manejo que permitan minimizar la acción de los mismos (16).

Myzus persicae puede invernar en forma partenogenética sobre hospederos secundarios (anholocíclico) en lugares donde las temperaturas invernales lo permiten $(9,15)$. En áreas con inviernos muy rigurosos, necesita la presencia de hospederos primarios para invernar en el estado de huevo (holocíclico). Sin embargo, existen situaciones intermedias en que ambas formas biológicas pueden coexistir (4).

El duraznero (Prunus persica) es el principal hospedero primario de $M$. persicae aunque existen otros hospederos primarios de menor importancia (21).

En Argentina, se ha informado el pasaje invernal sobre tres especies del género Prunus (7) y Lycium halimifolium, una especie de la familia Solanaceae, utilizada como hospedero primario en Europa (21). Sin embargo, M. persicae, también puede coexistir con formas anholocíclicas que invernan en plantas bianuales o perennes que permanecen verdes durante la estación fria. Estas especies pertenecen principalmente a las familias Cruciferae y Compositae (14).

La importancia de este fenómeno, radica en que los migrantes de Primavera, pueden volar más temprano en la estación cuando se originan en hospederos secundarios (20) pudiendo llegar a los cultivos de papa cuando las plantas son más sensibles al PVY (19). Además, los alados originados en hospederos secundarios, tienen más posibilidad de llegar a los cultivos portando virus que aquellos originados en hospederos primarios (23).

Se han realizado numerosos intentos por encontrar características que permitan diferenciar a las hembras vivíparas aladas originadas en durazneros (fundatrígenas) de aquellas aladas que se originan en hospederos secundarios (alienícolas) $(3,25,26)$. Es así como se han encontrado diversos índices que caracterizan a una y otra forma biológica de $M$. persicae (25) y que hacen posible diferenciarlas en material obtenido en trampas amarillas de agua (TAA) o trampas de succión.

El presente trabajo, fue dirigido a establecer la importancia relativa en la dispersión del PVY de cada una de las formas mencionadas dentro de un área restringida a la producción de tubérculos semilla de papa. 


\section{MATERIALES Y METODOS}

Descripción del área de trabajo: El trabajo se llevó a cabo en el departamento de Malargüe, al sudoeste de la provincia de Mendoza (Argentina), ubicado entre los $34^{\circ} 40^{\prime}$ y $37^{\circ} 40^{\prime}$ de latitud sur y los $68^{\circ} 15^{\prime}$ y $70^{\circ} 15^{\prime}$ de longitud oeste.

Malargüe constituye una de las áreas diferenciadas para la producción de tubérculos semilla de papa certificada en la República Argentina. Se trata de un área desértica al pie de la cordillera de los Andes con una precipitación media anual inferior a los $200 \mathrm{~mm}$. Las temperaturas mínimas en invierno pueden alcanzar $-23^{\circ} \mathrm{C}$ y las máximas en verano los $38^{\circ} \mathrm{C}$.

Los cultivos de papa se realizan con riego artificial y estos se desarrollan entre los meses de octubre y abril. El estudio se efectuó en dos localidades del departamento Malargüe: Ciudad y Las Chacras. En la primera, se sabe que existen alrededor de 2000 plantas de duraznero mientras que en Las Chacras no existe ningún individuo de este hospedero primario de $M$. persicae.

Ciclo biológico de Myzus persicae: Con la finalidad de establecer los posibles hospederos que tiene $M$. persicae en Malargüe, se realizó una inspección sistemática de posibles hospederos primarios y secundarios de este áfido entre agosto de 1989 y mayo de 1990. La inspección se realizó en algunos casos en forma visual en el campo y colecta de áfidos en etanol $75 \%$, otras veces observando el material vegetal en el laboratorio o golpeando el material sobre una superficie blanca para provocar el desprendimiento de los áfidos de las plantas. En todos los casos la identificación se realizó bajo lupa binocular. La frecuencia de muestreo respondió a la oportunidad de hallazgo de hospederos y a la densidad y distribución de los mismos en el campo. La oportunidad se refiere a que en el caso de hospederos poco comunes, fueron inspeccionados cada vez que se los encontró. La dependencia de la densidad y presencia, se refiere a que en algunos casos se encontraron poblaciones de plantas abundantes y continuas en el espacio y otras veces se encontraron individuos aislados o en escaso número. En este último caso, se inspeccionaron todos los individuos, mientras que en el primer caso, se inspeccionaron entre 50 y 100 individuos de la población.

Los posibles hospederos primarios (Prunas spp. y Lycium chilense) fueron inspeccionados cada 15 días desde el 15 de agosto de 1989 hasta el 30 de abril de 1990 .

Con la finalidad de conocer cada una de las etapas del ciclo biológicos de $M$. persicae sobre su hospedero primario, se revisaron 10 brindillas de duraznero semanalmente, desde el $1^{\circ}$ de septiembre de 1989 hasta el 30 de enero de 1990. Desde el 15 de marzo hasta la caída total de hojas, se efectuaron tres revisiones semanales. 
Análisis morfométrico de individuos alados de $M$. persicae: Se realizó sobre los individuos alados de $M$. persicae capturados en dos trampas amarillas de agua (TAA) (13) ubicadas una en la ciudad de Malargüe y otra en la localidad de Las Chacras, $15 \mathrm{~km}$ al sur de la primera. Las trampas fueron colectadas tres veces por semana y los áfidos conservados en etanol $75 \%$ hasta su montaje en portaobjeto.

El análisis se realizó en el Laboratorio de Entomología de la Facultad de Ciencias Agrarias de la Universidad Austral de Chile según la técnica propuesto por Eastop y Van Emden (6). Se analizaron todos los alados de esta especie capturados desde el comienzo de la actividad de vuelo hasta el 15 de enero de 1990. Con el objeto de establecer índices discriminatorios dentro de las poblaciones locales de $M$. persicae alados, fueron sometidos al análisis morfométrico, 23 individuos alados obtenidos directamente sobre durazneros (fundatrígenas) el 20 de octubre de 1989.

Utilizando los valores determinados Woodford y Lerman (25), se estableció la proporción de fundatrígenas y alienícolas en los individuos capturados en las TAA de la Ciudad y Las Chacras. Para ello se midieron, en cada individuo, los siguientes caracteres:

C1: Longitud de la fenestra en la mancha dorsoabdominal.

C2: Ancho de la fenestra.

C3: Longitud media de los cornículos.

C4: Ancho máximo medio de la mitad distal de los cornículos.

C5: Ancho mínimo medio de la mitad proximal de los cornículos.

C6: Longitud media del fémur III.

Las mediciones se realizaron utilizando diferente aumento del microscopio según el Caso. Cl, C2, C4 y C5 se obtuvieron con un aumento de 1000 X, C3 y C6 con $100 \mathrm{X}$.

El número de tubérculos abdominales y el diámetro del tubérculo lateral del segmento IV, dos parámetros que han sido utilizados por oros autores para separar fundatrígenas de alienícolas $(25,26)$ no pudieron ser considerados por fallas en el montaje que dificultaron estas mediciones.

El carácter C6 (longitud media del fémur III), fue utilizado como un índice del tamaño de cada individuo. Los valores de C3 (longitud media de los cornículos), fueron expresados como relacionados con C6 para estandardizar las variaciones de tamaño entre especímenes. La relación fue usada para expresar el grado de "hinchazón" de los cornículos.

De la combinación de los parámetros establecidos, se derivaron las variables de discriminación siguientes:

$$
\mathrm{V} 1=\mathrm{C} 2 / \mathrm{C} 1 \quad \mathrm{~V} 2=\mathrm{C} 3 / \mathrm{C} 6 \quad \mathrm{~V} 3=\mathrm{C} 4 / \mathrm{C} 6
$$

Los índices utilizados para discriminar entre fundatrígenas y alienícolas, fueron los propuestos por Woodford y Lerman (25) (Tabla 1). 
Tabla 1. Índices morfométricos utilizados para la diferenciación entre alienícolas y fundatrígenas aladas de M. persicae

\begin{tabular}{|c|c|c|c|}
\hline & VI & $\mathrm{V} 2$ & V3 \\
\hline Fundatrígenas & $\leq 0.35$ & $\leq 0.58$ & $\leq 1.25$ \\
\hline Alienícolas & $>0.35$ & $>0.58$ & $>1.25$ \\
\hline
\end{tabular}

La separación de ambas formas biológicas de $M$. persicae se basó en tres criterios, considerando fundatrígenas los siguientes casos

a. Todos aquellos individuos cuyos valores para V1, V2 y V3 respondieron a los valores de Woodford y Lerman (25).

b. Aquellos individuos en los que, por fallas en el montaje, no se pude obtener el valor de V1, pero cuyos V2 y V3 correspondieron a esta forma biológica,

c. Aquellos individuos cuyas relaciones de V2 y V3 correspondían al de una fundatrígena, aún cuando la relación de V1 no correspondiera.

Estos criterios fueron adoptados basándose en que V2 y V3 presentan los índices más consistentes para la discriminación de formas biológicas de $M$ persicae $(25,26)$.

\section{RESULTADOS}

Ciclo Biológico de $M$. persicae: Este áfído fue encontrado colonizando 25 diferentes especies pertenecientes a 12 familias botánicas (Tabla 2). Con anterioridad al primer registro de $M$. persicae en trampas amarillas de agua (20 de septiembre), se encontraron colonias de este áfido sobre cinco especies (Tabla 2) por lo Que se considera que invernaron en forma partenogenética sobre las mismas.

De las seis especies del genero Prunus inspeccionadas en la temporada 1989-90 (P. aviuni, P. armen i acá, $P$. cerozus, $R$. domestics, $R$. pérsica y $P$. pissardii) solamente estas dos últimas fueron colonizadas por $M$. persicae. Lycium chilense no fue colonizada por este áfido durante el período de inspección de plantas. La observación periódica de brindillas de durazneros ubicados en Ciudad, permitió establecer el comienzo de las diferentes etapas del ciclo biológico de $M$. persicae estas fueron las siguientes:

- Aparición de hembras fundatrices: 10 de septiembre

- Aparición de hembras Fundatrígenas ápteras 4 de octubre

- Fundatrígenas con esbozos alares: 13 de octubre.

- Fundatrígenas aladas: 20 de octubre -Ginóparas aladas: 5 de abril

- Huevos: 24 de abril 
Tabla 2. Especies y familias botánicas utilizadas como hospederos por M. persicae en Malargüe (1989-1990).

FAMILIA

Especie

\section{AMARANTACEAE}

Amaranthus quitensis HBK

CHENOPODIACEAE

Chenopodium album Linnaeus

COMPOSITAE

Anthemis cotula Linnaeus

* Calendula officinalis Linnaeus

* Carduus nutans Linnaeus ssp. macrolepis (Patern)

Xanthium spinosum Linnaeus

Zima elegans Linnaeus

CONVOLVULACEAE

Convolvulus arvensis Linnaeus

CRUCIFERAE

* Brassica campestris Linnaeus

Brassica olerácea Linnaeus var. capitata Linnaeus

* Eruca sativa Gars.

CUCURBITACEAE

Curcubita spp Linnaeus

ESCROFULARIACEAE

Antirhinum majus Linnaeus

LILIACEAE

Tulipa sp.

MALVACEAE

* Malva parviflora Linnaeus

Malva sylvestris Linnaeus

POLIGONACEAE

Rumex crispus Linnaeus

ROSACEAE

Fragancia chiloensis Duch

Prunus persica (Linnaeus) Batsch

Prunus pissardii Carr

SOLANACEAE

Datura ferox Linnaeus

Solanum eleagnifolium Car.

Solanum sublobatum Wild ex Schult

Solanum tuberosum ssp. tuberosum Linnaeus

URTICACEAE

Urtica urens Linnaeus

* Hospederos secundarios de M. persicae presentando colonias antes de la primera captura en TAA. 
Análisis morfométrico: Los índices morfométricos de los 23 individuos obtenidos sobre duraznero (fundatrígenas), presentan diferentes grados de coincidencia con los índices tomados de la literatura (25). El índice V1 (abertura de la fenestra) solamente coincidió en un 56\% de los individuos $(<0.35)$ mientras que V2 (longitud de los cornículos) y V3 (grado de hinchazón de los cornículos) coincidieron en un $100 \%$ y $86 \%(<0.58$ y $<1.25)$ respectivamente.

La utilización de los índices morfométricos (Tabla 1) permitió definir el origen biológico de $105(70.5 \%)$ de los 149 individuos capturados en TAA. De estos 105 individuos, $22(20.9 \%)$ fueron clasificados como fundatrígenas y $83(79.1 \%)$ como alienícolas. La Tabla 3 muestra los resultados obtenidos con el material de Ciudad y Las Chacras.

Tabla 3. Proporción de formas holocíclicas (fundatrígenas) y anholocíclicas (alienícolas) en dos localidades de Malargüe.

\begin{tabular}{llrrrr}
\hline \multicolumn{1}{c}{ Localidad } & \multicolumn{2}{c}{ Fundatrígenas } & & Alienícolas & Total \\
& $\mathrm{N}^{\circ}$ & $\%$ & $\mathrm{~N}^{\circ}$ & $\%$ & $\mathrm{~N}^{\circ}$ \\
\hline Ciudad & 6 & 20.00 & 24 & 80.00 & 30 \\
Las Chacras & 16 & 21.33 & 59 & 79.67 & 75 \\
Total & 22 & 20.90 & 03 & $7 \mathrm{Y} 10$ & 105 \\
& & & & & \\
\hline
\end{tabular}

La proporción de fundatrígenas y alienícolas, presentó variaciones en el tiempo tanto en Ciudad como en Las Chacras. Las primeras capturas de $M$. persicae en esta última, resultaron ser fundatrígenas (de hospederos primarios) en su totalidad. En Ciudad, las capturas más tempranas estuvieron conformadas por partes aproximadamente iguales de ambas formas (Tabla 4).

Tabla 4. Variación de la proporción de fundatrígenas (F) y alienícolas (A) de M. persicae capturadas en dos localidades de Malargüe (expresada en \%).

\begin{tabular}{|c|c|c|c|c|c|c|}
\hline \multirow[t]{2}{*}{ Fecha } & \multicolumn{2}{|c|}{ Ciudad } & \multicolumn{2}{|c|}{ Las Chacras } & \multicolumn{2}{|c|}{ Total } \\
\hline & (F) & (A) & (F) & (A) & (F) & (A) \\
\hline 09/10-20/10 & 44.4 & 56.4 & 100.0 & 0.0 & 50.0 & 50.0 \\
\hline $24 / 10-06 / 11$ & 50.0 & 50.0 & 100.0 & 0.0 & 66.6 & 33.4 \\
\hline 07/11-20/11 & 0.0 & 100.0 & 22.2 & 77.8 & 20.0 & 80.0 \\
\hline 21/11-04/12 & 0.0 & 100.0 & 14.9 & 85.2 & 11.4 & 88.6 \\
\hline 05/12-10/12 & 0.0 & 100.0 & 5.1 & 94.7 & 5.0 & 95.0 \\
\hline $19 / 12-01 / 01 *$ & - & $\longrightarrow$ & 0.0 & 100.0 & 0.0 & 100.0 \\
\hline 02/01-15/01 & 0.0 & 100.0 & 0.0 & 100.0 & 0.0 & 100.0 \\
\hline $16 / 01-29 / 01$ & 0.0 & 100.0 & 0.0 & 100.0 & 0.0 & 100.0 \\
\hline
\end{tabular}

* No se obtuvo material analizable para esa fecha en Ciudad. 
La proporción de fundatrígenas disminuyó con el tiempo tanto en Ciudad como en Las Chacras. En la primera localidad, se alcanzó un $100 \%$ de alienícolas el 20 de noviembre mientras que en Las Chacras, esta situación se verificó recién el 1 de enero.

\section{DISCUSIÓN}

A partir de la información obtenida en las diferentes etapas de la investigación, pudo establecerse que en Malargüe, M. persicae se comporta como holocíclico y anholocíclico, es decir que una parte de la población utiliza hospederos primarios para invernar como huevo y otra parte inverna como hembra vivípara sobre hospederos secundarios que permanecen verdes durante el invierno, especialmente Cruciferae (Brassica spp. y Eruca sativa) y Compositae (Carduus nutans y Calendula officinalis). Este tipo de comportamiento biológico, ha sido verificado para Nueva Zelandia (4) y otras partes del mundo donde las condiciones climáticas permiten ambas formas invernantes.

La forma sexual de pasaje invernal, ha sido informada para la provincia de Mendoza (7) citándose como hospederos primarios además del duraznero $(P$. persica), al ciruelo $(P$. domestica) y al damasco $(P$. armeniaca). Sin embargo, estas dos últimas especies, no fueron encontradas colonizadas por $M$. persicae en Malargüe durante el periodo en que se llevó a cabo la investigación. $\mathrm{Si}$ se encontró una colonia de individuos ápteros sobre $P$. pissardii lo que podría indicar que la especie mencionada puede ser utilizada como hospedero primario.

Lycium halimifolium, es una Solanaceae utilizada como hospedero primario por M. persicae en Europa (21). En Malargüe existe una especie del mismo género (L. chilensis) formando parte de la vegetación autóctona. Esta especie, tampoco presentó colonias de M. persicae durante el período de estudio.

El análisis morfométrico de las primeras capturas de M. persicae en Ciudad y en Las Chacras, arrojó una proporción similar de ambas formas en la primera y un $100 \%$ de fundatrígenas en la segunda, donde no hay durazneros. Vale decir que la primera actividad de este áfido en Las Chacras, se registra a partir de poblaciones originadas en hospederos primarios. Estos hechos están en desacuerdo con algunos antecedentes (20) que señalan que las formas anholocíclicas que invernan sobre hospederos secundarios, comienzan su actividad de vuelo más temprano en la estación.

La aparición de formas aladas está regida por numerosos factores (5) siendo los más importantes la temperatura, la calidad nutricional del hospedero y la densidad de la población (efecto de "crowding"). Puesto que las temperaturas invernales en Malargüe son muy bajas (hasta $-23^{\circ}$ ), es posible que sobrevivan sólo algunos pocos individuos de las formas anholocíclicas sobre hospederos secundarios. 
Esta situación demoraría las condiciones de alta densidad ("Crowding") y consecuentemente la aparición de formas aladas. Sobre durazneros, en cambio, la oviposición es abundante y en consecuencia las poblaciones primaverales también lo son. Esto determinaría la aparición de formas aladas sobre los durazneros con anterioridad a los hospederos secundarios. Las temperaturas primaverales y la calidad nutricional no influyen ya que las primeras son iguales para ambos hospederos y la calidad nutricional es adecuada en esa época del año.

En Holanda, mediante la utilización de índices morfométricos, se demostró que la mayoría de los migrantes de primavera que llegan a los cultivos de papa, son originados en hospederos primarios (10) lo que coincide con los resultados obtenidos en Malargüe. En cambio en Inglaterra, sobre 228 hembras aladas capturadas en primavera y analizadas morfométricamente, solamente dos resultaron ser anholocíclicas (5).

Los individuos holocíclicos de $M$. persicae que inician la actividad de esta especie en Las Chacras donde no hay hospederos primarios, deben originarse en los durazneros de Ciudad o bien en otros oasis más alejados. La mayor capacidad de vuelo de las fundatrígenas sobre las alienícolas (24), determinaría esta situación.

Las hembras fundatrígenas provenientes de durazneros, y que dan comienzo a la actividad de $M$. persicae en esta localidad, tienen especial significación epidemiológica para la dispersión del PVY si se considera su ocurrencia en el tiempo. Entre el 23 de octubre y el 6 de noviembre, la totalidad de los M persicae capturados en TAA, correspondieron a fundatrígenas. En ese momento, se encuentran emergiendo los cultivos implantados a mediados de octubre. Dada la alta sensibilidad de las plantas de papa al PVY en sus primeros estados de desarrollo (19), los áfidos que lleguen al cultivo ocasionaron una dispersión temprana del virus, ya sea a partir de fuentes de infección externas (plantas voluntarias de papa) o a partir de algunas plantas provenientes de tubérculos semilla enfermos. El PVY puede sufrir una nueva dispersión a partir de estas plantas infectadas primariamente, aproximadamente un mes más tarde (1). Si tenemos en cuenta que el primer pico de máxima presión de vectores se verifica en Malargüe durante la primera semana da diciembre (14), la dispersión del PVY a partir de las plantas infectadas por las fundatrígenas a comienzos del ciclo, puede ser muy importante.

A pesar de haberse constatado la ocurrencia de formas anholocíclicas de $M$. persicae en Malargüe, la presencia de hospederos primarios en algunas localidades puede ser determinante del volumen de las poblaciones de individuos alados durante el ciclo de los cultivos de papa. Puesto que las hembras fundatrígenas aladas presentan una mayor capacidad de vuelo que las alienícolas (24), la existencia de durazneros posibilita la dispersión de los áfidos a grandes distancias para colonizar cultivos o malezas, que funcionarán como fuentes de individuos alados durante el resto de la estación. 
Dentro de las estrategias para el manejo integrado de áfidos (17), el control de los mismos sobre sus hospederos primarios antes de la aparición de formas aladas puede resultar en una importante disminución de las poblaciones que vuelan sobre los cultivos de papa. A la luz de la información obtenida en el presente trabajo, se observa que la presencia de durazneros (Prunus persica) en áreas dedicadas a la producción de tubérculos semilla de papa, es relevante en la dispersión temprana del PVY. Las aspersiones primaverales de los durazneros con insecticidas o la eventual erradicación de todos los ejemplares existentes, cuando, como en el caso de Malargüe, no se trata de montes comerciales, puede contribuir a una sensible disminución en los niveles de infección con PVY de los tubérculos semilla obtenidos.

Por último, el análisis morfométrico de alados de $M$. persicae (25) capturados en TAA, provee un método eficiente para estimar la incidencia de las diferentes formas biológicas de este áfido en la dispersión del PVY.

\section{REFERENCIASBIBLIOGRÁFICAS}

1. Beemster, A.B.R. 1979. Acquisition of the potato viruses $\mathrm{Y}^{\mathrm{n}}$ by Myzus persicae from primarily infected "Bintje" potato plants. Neth. J. PI. Path. $85: 75-81$.

2. Blackman, R.L.; Eastop, VF. 1984. Aphids on the world's crops. An identification guide. John Wiley and Sons (ed.). Chichester. 466 p.

3. Broadbent, L.; Heathcote, G.D. 1955. Sources of overwintering Myzus persicae (Sulzer) in England. Plant Patol. (London) 4:135-137.

4. Cotier, W. 1953. Aphids of New Zeland. N.Z. Dept. Sci. Ind. Res. Bull. $106.382 \mathrm{p}$.

5. Dixon,G. 1985. Aphid ecology. Blackie, Glasgow, 157 p.

6. Eastop, V.F.; Van Emden, H.F. 1972. Aphid tecnology. Academic Press, London. 344 p.

7. 7.Espul, J.C.; Mansur, P.S. 1968. Reproducción sexual del “pulgón verde del duraznero" Myzus persicae (Sulz.) en Mendoza (Argentina). RIA Serie 5, Patologia Vegetal 6 (V): 61-71.

8. Harrewijn, P; Minks, A.K. 1990. Integrated Aphid Management: General Aspects. In. Minks, A.K. y Harrewijn, P. (ed.). Aphids, their biology, natural enemies and control. Vol. C. Elsevier, Amsterdam. p.267-272.

9. Heinze, K. 1939. Zur Biologie und Systematik der Virusübertrageden Blatthause. Mitt. Biol. Reinchst. 59: 35-49. 
10. Hille Ris Lambers, D. 1955. Potato aphids and virus diseases in the Netherlands. Ann. appl. Biol. 42:355-360.

11. Hule Ris Lambers, D. 1980. Pulgones: sus ciclos biológicos y su papel como vectores de virus. P. 25-53 In. De Bokx, J. A. (ed.) Virosis de la papa y de la semilla de papa. Buenos Aires Hemisferio Sur, 301 p.

12. Hooker, WJ. 1980. Compendio de enfermedades de la papa. Centro Internacional de la Papa, Lima, Perú. 166 p.

13. Moericke, V. 1951. Eine Farbfalle zur Konttolle des fluges von Blattlausen, insbesondere der Pfirsichblatlaus. Nachrichtenbl. Deut. Pflanzenchutzdiest Berlin3:23-24.

14. Ortego, J. 1992. Presencia y actividad de áfidos vectores de PVY en dos localidadec productoras de tubérculo-semilla de papa en Malargüe, Mendoza, Argentina. Revista ALAP (en prensa).

15. Ossianilson, F. 1966. Insects in the epidemiology of plant viruses. Ann. Rev. Entomol. 11:213-232.

16. Salazar, L. F. 1982. Enfermedades virosas de la papa. Centro Internacional de la Papa, Lima, Perú. 11 p.

17. Schepers, A. 1980. Control de los pulgones vectores en Holanda. P. 211220. In. De Bokx, J.A. (ed.) Virosis de la papa y de la semilla de papa. Buenos Aires, Hemisferio Sur, 303 p.

18. Sigvald, R. 1984. The relative efficiency of some aphid species as vectors of Potato virus $\mathrm{Y}^{\circ}\left(\mathrm{PVY}^{\circ}\right)$. Potato Res. 27: 285-290.

19. Sigvald, R. 1985. Nature plant resistance of potato plants against potato virus $\mathrm{Y}^{\circ}\left(\mathrm{PVY}^{\circ}\right)$. Potato Res. 28:135-143.

20. Swenson, K.G. 1968. Role of aphids in ecology of plant viruses. Ann. Rev. Phytopathol.6:351-374.

21. Van Emden, H.F.; Eastop, V.F.; Hughes, R.D.; Way, M.S. 1969. The ecology of Myzus persicae. Ann. Rev. Ent. 14: 197-270

22. Van Harten, A. 1983. The relation between aphid flights an the spreed of potato virus $\mathrm{Y}^{\mathrm{n}}\left(\mathrm{PVY} \mathrm{Y}^{\mathrm{n}}\right)$ in the Netherlands. Potato Res. 26:1-15.

23. Wallis, M.A. 1967. Some host plants of the green peach aphid and beet western yellow virus in the Pacific North-West. J. Econ. Entomol. 60: 904-907. 
24. Woodford, J.A.T. 1969. Diference in flight capacity between naturally occurring spring and summer forms of Myzus persicae (Sulz.) (Hemiptera: Aphididae). Nature 217:583-594.

25. Woodford, J.A.T.; Lerman, P.M. 1974. Morfological variation in spring migrants of Myzus persicae (Sulz.) (Hemipthera: Aphididae): comparison of alate from peach and mangold. Bull. Ent. Res. 64: 595604 .

26. Woodford, J.A.T. 1977. The efiect of genotipe, environment, age and morph on morphological variation in alate Myzus persicae (Sulzer) (Hemiptera: Aphididae). Bull. ent. Res. 67:685-693. 